\title{
As novas faces do socialismo burguês
}

Sobre uma categoria do Manifesto de 1848, os novos movimentos sociais e seus intelectuais.

Eurelino Coelho ${ }^{1}$

Já não há mais nenhuma novidade em discutir os assim chamados novos movimentos sociais (NMS), posto que nos últimos anos, graças aos esforços de um conjunto crescente de intelectuais, este tema conquistou seu espaço nas bibliotecas de Ciências Humanas e no debate público. Este texto problematiza as abordagens praticadas por intelectuais que se ocuparam do assunto, priorizando questões pertinentes à crítica do marxismo contida na maioria delas.

Quando da publicação do Manifesto do Partido Comunista de 1848, um dos cuidados tomados por seus redatores foi demarcar as diferenças entre o programa proposto pela Liga Comunista e os vários projetos de socialismo já lançados nas arenas políticas da Europa. São bem conhecidas as análises de Marx e Engels na terceira seção do Manifesto (Literatura Socialista e Comunista) sobre o socialismo reacionário (o feudal, o pequeno-burguês e o "verdadeiro socialismo" dos intelectuais alemães), o socialismo conservador ou burguês e o socialismo e comunismo crítico-utópicos.

Na metade do século XIX a luta pelo socialismo, do modo como a compreendiam Marx e Engels, exigia esta demarcação por razões prático-políticas, mais do que teóricas. Ainda que o debate tenha tido sempre uma importante dimensão teórica, a dimensão mais importante do conflito, porque explica a sua própria emergência como conflito teórico relevante, foi a política. O que estava em questão era a necessidade de

1Professor da UEFS/BA e pesquisador do LDH/UFF.

cadernos cemarx, $n^{0} 2-2005 \mid \mathbf{9}$ 
enfrentar politicamente as implicações das concepções socialistas adversárias sobre as lutas reais da classe operária e, por conseguinte, sobre a sua formação.

Não é surpreendente que esta necessidade permaneça atual no século XXI. Na verdade, ao longo de mais de 150 anos de história posterior ao Manifesto, os campos de batalha pelo socialismo encontraram-se quase sempre ocupados por um número considerável de concepções e projetos políticos que se reivindicam como socialistas se bem que hoje este termo pareça estar cedendo terreno para a designação mais genérica de "esquerda". Hoje, como no tempo de Marx, a direção e o sentido das lutas dos trabalhadores dependem não só das circunstâncias objetivas em que se travam os combates, mas também do modo como estes conflitos reais são percebidos e interpretados pela própria classe trabalhadora. Por isso continuam em operação as demarcações e as formas de relacionamento entre grupos que elas traçam e qualquer intervenção marxista nos conflitos (práticos e teóricos) contemporâneos precisa tomá-las seriamente em conta.

O que, no entanto, pode sim parecer surpreendente é descobrir que toda a riqueza das conflituosas experiências políticas de luta pelo socialismo após Marx e Engels não foi suficiente para produzir concepções não-marxistas de tipo novo, com a parcial exceção de algumas variedades de socialismo pós-moderno. As bases argumentativas das modalidades contemporâneas de esquerda não-marxista remetem, quase sempre, às mesmas idéias fundamentais submetidas à crítica nas páginas do Manifesto. Isto não impede, evidentemente, que estas teses vejam a si mesmas como autênticas novidades.

Na fronteira, nem sempre nítida, entre os terrenos da política e do pensamento social acadêmico, situa-se a produção intelectual sobre os chamados novos movimentos sociais. Trata-se de uma das formas da esquerda contemporânea, embora não, evidentemente, de uma organização partidária comum, mas de um movimento intelectual com estreitas relações com o mundo da política. Seus agentes são aqui denominados os intelectuais dos novos movimentos sociais. Um estudo mais aprofundado deste movimento intelectual precisaria inicialmente investigar como algumas formas assumidas pelas lutas sociais proporcionaram a emergência e a consolidação da problemática dos chamados novos movimentos sociais em algum momento entre os anos 70 e 80 . A consolidação da problemática e do seu corpo conceitual específico, por sua vez, articula-se intimamente com a construção de um campo de atuação para profissionais das ciências humanas, a maioria professores universitários. Estas questões, algumas das quais já foram postas de algum modo por outros pesquisadores, ultrapassam as possibilidades deste texto, que se dedica a algo bem mais modesto: pretendemos apenas estabelecer as

10 As novas faces do socialismo burguês 
linhas de parentesco entre as teses destes intelectuais contemporâneos e seus primos do século XIX, os socialistas burgueses mencionados no Manifesto.

A denominação empregada - intelectuais dos movimentos sociais - é bastante imprecisa, mas a escolha teve suas razões. A expressão permite identificar o grupo de intelectuais que privilegiou a temática dos novos movimentos sociais e que é responsável pela sedimentação da forma hoje predominante de compreensão do fenômeno. Por outro lado, estamos nos reportando a um conjunto específico de intelectuais que, em sua maioria, se relacionam organicamente com os movimentos sociais que eles tematizam - neste sentido, são intelectuais desses movimentos. Há, decerto, muita diversidade nas abordagens desenvolvidas por eles, mas há certos pontos de confluência em suas obras que são suficientes para identificar uma matriz teórica comum.

As reflexões desenvolvidas aqui dizem respeito a um corpus que julgamos ser capaz de documentar a matriz teórica compartilhada pelos autores que selecionamos em razão de os considerarmos representativos do conjunto. ${ }^{2}$ Certamente esta seleção não cobre todas as abordagens dos NMS, talvez nem mesmo a maior parte. É, no entanto, suficiente para configurar as linhas mestras do quadro conceitual predominante dentro do qual o tema vem sendo tratado. O que escapa destes parâmetros são, de fato, vozes dissonantes e minoritárias, independente de sua melhor ou pior capacidade de interpretação.

A vinculação orgânica destes intelectuais com os movimentos a respeito dos quais eles escrevem é uma das dimensões cruciais a serem observadas. Em razão desses laços orgânicos, o impacto do produto do seu trabalho vai muito além do alcance normal das teses e artigos científicos, que atingem um público quase sempre restrito aos circuitos universitários. Atuando no interior mesmo dos movimentos, sobretudo junto a dirigentes e equipes de assessores, estes intelectuais estão em condição de influenciar decisivamente nos processos pelos quais os agentes históricos - os mili-

$-\cdots-\cdots$

20 corpus é constituído das seguintes obras: Sonia Alvarez, Evelina Dagnino e Arturo Escobar (orgs.) Cultura Política nos Movimentos Sociais Latino-Americanos. Belo Horizonte, UFMG, 2000; Joanildo A. Burity (org.) Cultura e Identidade: perspectivas interdisciplinares. Rio de Janeiro, DP\&A, 2002; Breno A. S. M. Fontes (org.) Movimentos Sociais: produção e reprodução de sentido. Recife, UFPE, 1999; Maria da Glória Gohn. Teorias dos Movimentos Sociais. 2a. ed., S. Paulo, Loyola, 2000; Sônia Laranjeira (org.) Classes e Movimentos Sociais na América Latina. S. Paulo, Hucitec, 1990; Jean Rossiaud e Ilse Scherer-Warren. A Democratização Inacabável. Petrópolis, Vozes, 2000; Ilse Scherer-Warren e Paulo J. Krischke (orgs.) Uma Revolução no Cotidiano? S. Paulo, Brasiliense, 1987; Ilse Scherer-Warren. Redes de Movimentos Sociais. 2a. ed. S. Paulo, Loyola, 1996.

cadernos cemarx, $\mathrm{n}^{0} 2-2005 \mid \mathbf{1 1}$ 
tantes dos movimentos - atribuem sentido a suas ações coletivas efetivas. Trata-se de uma atividade de caráter estratégico, na medida em que interfere ao nível da práxis dos movimentos: influi sobre a consciência que os militantes constróem sobre a sua própria prática política. Esta consciência da prática é decisiva para orientar a própria prática, ajuda a definir seus objetivos, seus rumos e ritmos.

Pode-se perceber mais facilmente a importância desta atividade intelectual em situações reais. Pensemos nas lutas populares por melhores condições de moradia e transporte, ou contra a carestia, que se intensificaram nas grandes cidades brasileiras nos anos 70. Aqueles foram confrontos travados por sujeitos contra formas de carência material que resultavam do fato de que se apropriavam somente de uma parcela desproporcionalmente pequena da riqueza social. Esta situação, por sua vez, é determinada pela condição de classe: não sendo proprietários dos meios de produção, somente podem adquirir os meios de sobrevivência com aquilo que obtém mediante a venda da sua própria força de trabalho. As condições em que esta venda tem de ser realizada (que podem variar muito, chegando até à situação de não encontrar comprador) e mais os mecanismos de exploração do trabalho podem determinar uma forte deterioração do preço desta mercadoria, o que se expressa como restrição do poder de adquirir meios de vida, ou seja, carência material. Se é assim, a luta contra a alta de preços dos alimentos ou pelo direito de morar são formas de luta contra situações de carência que decorrem do próprio modo capitalista de produção e que afligem aqueles que, possuindo ou não vínculos formais de emprego, vivem do seu próprio trabalho.

A protagonista dessas lutas específicas é, pois, a classe trabalhadora. Mesmo quando, nos conflitos, os protagonistas não se referem a si mesmos como classe trabalhadora (e sim como moradores de favela ou usuários de trens suburbanos, por exemplo) a objetividade da sua condição de classe é inescapável. Sem a desigualdade histórica de classes, tais conflitos pela apropriação da riqueza social nem sequer ocorreriam.

Para os teóricos dos movimentos sociais, no entanto, aquelas não são formas da luta de classes, mas batalhas pela ampliação da cidadania, pelo reconhecimento público do direito de todos a ter direitos. ${ }^{3}$ Um dos principais argumentos levantados

\section{- . - . . -}

3 Por outro lado, a historiografia marxista inglesa, particularmente as obras de E. P. Thompson e os trabalhos de Eric Hobsbawm sobre o "mundo do trabalho" têm ajudado vários pesquisadores a perceber as múltiplas dimensões da vida social como constitutivas da experiência de classe. É desta perspectiva que, por exemplo, Marcelo Badaró fala em "trabalhar e viver" na cidade como aspectos da experiência de classe. Cf. Marcelo Badaró. Novos e Velhos Sindicalismos. Rio de Janeiro, Vício de Leitura, 1998.

12 As novas faces do socialismo burguês 
pelos analistas que negam a determinação classista dos conflitos é o fato de que eles não se dirigem contra os capitalistas em geral, seus bancos ou empresas, mas sim ao Estado. Segundo esta linha de análise, o objetivo final dos movimentos seria a democratização do Estado e a mudança na natureza de suas relações com a sociedade civil.

A suposição implícita nas análises sobre as virtualidades da cultura política democrática engendrada pelos movimentos sociais é a de que o caráter de classe do Estado deixa de ter importância, tanto na teoria como na prática política.

É a própria noção de estado separado da sociedade que está em cheque aqui, na medida em que o debate público dos interesses da sociedade impede que se conceba, por exemplo, a economia como uma esfera sem sujeito, ou cujo sujeito é totalmente determinado pela lógica capitalista. ${ }^{4}$

O conceito gramsciano de Estado ampliado seria a base para pensar o Estado para além das determinações de classe, vistas como demasiado estreitas. A prioridade é que o Estado legitime e institucionalize os conflitos e, com isso, redefina sua relação com a sociedade. Estes são objetivos que se poderia alcançar com mudanças na cultura política e com a democratização do Estado, sem a necessidade de transformar a base dos conflitos sociais.

A "utopia democrática" consistiria na construção

entre Estado e sociedade, de arenas públicas que dêem visibilidade aos conflitos e ressonância às demandas sociais, permitindo, no cruzamento das razões e valores que conferem validade aos interesses envolvidos, a construção de parâmetros públicos que reinventam a política no reconhecimento dos direitos como medida de negociação e deliberação de políticas que afetam a vida de todos. ${ }^{5}$

Evidentemente não há como realizar aqui a extensa crítica que considero necessário

$--\cdots+-$

4 Sérgio Gregório Baierle. A Explosão da Experiência. Emergência de um novo princípio ético-político nos movimentos populares urbanos em Porto Alegre. In: Sonia Alvarez, Evelina Dagnino e Arturo Escobar (orgs.). Cultura Política nos Movimentos Sociais Latino-Americanos. Op. cit., p. 213.

5 Maria Célia Paoli e Vera da Silva Telles. Direitos Sociais. Conflito e negociações no Brasil contemporâneo. In: Sonia Alvarez, Evelina Dagnino e Arturo Escobar (orgs.). Cultura Política nos Movimentos Sociais Latino-Americanos, op. cit., p. 116.

cadernos cemarx, $n^{0} 2-2005 / 13$ 
fazer sobre essas idéias, inclusive sobre o emprego abusivo da noção de Estado ampliado. Limito-me a indicar linhas gerais de contestação, suficientes para prosseguir com meu argumento. É preciso reconhecer que, em sua relação com o Estado, os conflitos sociais podem assumir formas mais complexas, mais mediadas, sem deixar de ser, no entanto, expressão da luta de classes. A questão chave aqui diz respeito ao caráter do Estado. Segundo penso, a mera existência do Estado, em qualquer contexto histórico conhecido, indica a presença de algum tipo de dominação de classe. As importantes experiências de ampliação da participação em vários governos de esquerda no século XX, bem como as políticas públicas de distribuição de renda implicaram em alterações significativas da configuração do Estado e das lutas, mas não modificaram sua natureza de classe. Mesmo quando funcionou como arena de conflitos e ainda nos momentos em que apresentou soluções pontuais que foram ao encontro das aspirações das classes subalternas, ou seja, mesmo quando se ampliou, o Estado cumpriu, antes de tudo, seu papel de garantir a ordem que não era outra senão a ordem de dominação do capital. ${ }^{6}$

Quaisquer que sejam as suas incongruências, estas interpretações das lutas sociais, produzidas e difundidas pelos mencionados intelectuais, tendem a ser apropriadas e reproduzidas pelos próprios agentes dos movimentos sociais. A mais importante conseqüência da difusão desta forma de consciência é a desorganização política da classe subalterna no contexto da guerra de posição que lhe é imposta pela classe dominante. A única forma de lutar contra a hegemonia burguesa consiste em laborar na construção das formas da contra-hegemonia, o que só pode ser realizado mediante a explicitação dos conflitos de classe:

O que se pode contrapor, por parte de uma classe inovadora, a este complexo formidável de trincheiras e fortificações da classe dominante? O espírito de cisão, isto é, a conquista progressiva da consciência da própria personalidade histórica, espírito de cisão que deve tender a se ampliar da classe protagonista às classes aliadas potenciais: tudo isso requer um complexo trabalho ideológico, cuja primeira condição é o exato conhecimento do campo a ser esvaziado de seu elemento de massa humana ${ }^{7}$

$--\cdots$

6 Para uma discussão do Estado como uma das "personificações do capital" ver Istvan Mészaros. Para Além do Capital. São Paulo, Boitempo - Campinas, Edunicamp, 2002, especialmente o capítulo II (A Ordem da Reprodução Sócio-Metabólica do [apital).

7Antonio Gramsci. Cadernos do Cárcere, vol. 2, Rio de Janeiro, Civilização Brasileira, 2000, p. 79, grifos meus.

14 As novas faces do socialismo burguês 
"Espírito de cisão" significa o princípio, simultaneamente teórico e político, da estruturação de uma visão de mundo ("consciência da própria personalidade histórica”) e, conseqüentemente, de um projeto político antagônico à Weltanschauung dominante. É com base no "espírito de cisão" que se pode organizar o trabalho contra-hegemônico de "esvaziar" o campo inimigo do "seu elemento de massa humana", isto é, organizar a luta contra-hegemônica. O apagamento das referências de classe e luta de classes na interpretação das lutas sociais tem, portanto, o efeito de obstaculizar o desenvolvimento da luta contra-hegemônica da classe subalterna.

Os textos do corpus compartilham um certo mal-estar com o marxismo, que em alguns casos evolui para uma crítica aberta com caráter de ruptura. O quadro conceitual marxista, particularmente a centralidade da luta de classes, é abandonado ou obliterado por figuras teóricas apresentadas como mais compatíveis com a novidade histórica encarnada nos NMS. Alguns termos tornam-se categorias centrais neste novo quadro conceitual: cidadania, direitos, democracia, sociedade civil, esfera pública. A forma como vêm sendo empregados estes termos tem tido o efeito de circunscrever a discussão sobre os NMS ao terreno do pensamento liberal. Não por acaso a perspectiva de superação do capitalismo desaparece do horizonte das lutas sociais, tais como são concebidas por estes estudos. Expressões como "transformação social" ou "mudança" passam a designar arranjos novos no interior da ordem do capital.

Os sintomas deste mal-estar com o marxismo começaram a ficar mais evidentes na segunda metade dos anos 80 . Foi nesta época que começaram a aparecer análises participantes dos chamados "novos movimentos sociais" que, em suas críticas à "esquerda tradicional", reivindicavam um "novo paradigma" para o pensar e fazer política de esquerda. Tenho em mente os artigos reunidos por Ilse Scherer-Warren e Paulo Krischke em 1986 (publicados em 1987) num livro cuja segunda parte intitula-se "A Revisão dos Paradigmas". ${ }^{8}$ As críticas diretas ao marxismo que aparecem nos textos ainda são, na maioria das vezes, tímidas e com muitas reticências, como nesta passagem: "Não há dúvida de que o marxismo, principalmente do ponto de vista do seu método (...) continua trazendo sua contribuição para os movimentos sociais contemporâneos, mas perde a sua quase que exclusividade anterior". ${ }^{9}$ Con-

$-{ }_{-}-\ldots$

8llse Scherer-Warren e Paulo Krischke. Uma Revolução no Cotidiano? Os Novos Movimentos Sociais na América do Sul. Op. cit.

9llse Scherer-Warren. O Caráter dos Novos Movimentos Sociais. in: Ilse Scherer-Warren e Paulo Krischke. (orgs.) Uma Revolução no Cotidiano? Op. cit., p. 38.

cadernos cemarx, $\mathrm{n}^{0} 2-2005 \quad \mathbf{1 5}$ 
ceitos marxistas como classe e alienação aparecem em vários artigos, embora quase sempre acompanhados de ressalvas. A maioria dos autores, todavia, vê com simpatia o aparecimento das

novas correntes (modernidade e nova filosofia), que vêm realizando a crítica ao centralismo burocrático, ao autoritarismo e ao dogmatismo revolucionário presentes nos movimentos sociais tradicionais, contrapondo a estes movimentos novos projetos para a conquista de autonomias individuais e coletivas e que permitam a diversidade. ${ }^{10}$

O "novo paradigma" que é esboçado por vários artigos apóia-se nas "novas correntes" para louvar o caráter democrático das "identidades restritas" (não redutíveis a classes) dos movimentos e sua orientação "microrrevolucionária", voltada para as situações do cotidiano e "menos preocupadas em interagir com o Estado (no campo da política, em sentido amplo)". ${ }^{11}$ A "revolução no cotidiano" seria a "nova utopia" dos movimentos sociais.

A experiência teórica com diversas variantes das "novas correntes" prosseguiu no meio dos intelectuais dos novos movimentos sociais. Um ano depois da publicação desta coletânea, Benjamín Arditi foi convidado para um seminário sobre "Classes e Movimentos Sociais na América Latina" em Porto Alegre. Sua contribuição, depois publicada juntamente com os textos dos demais expositores, era uma defesa da "condição pós-marxista" na discussão sobre o socialismo. Ele aplica a abordagem estruturalista desenvolvida por Thomas Kuhn sobre a crise dos paradigmas científicos para afirmar que o "paradigma marxista" teria sido quebrado pela democratização do Estado no século XX e pela ativação de novos espaços sociais e políticos com os quais o marxismo não conseguiria lidar. O socialismo "pós-marxista" teria que ser radicalmente democrático, teria que reconhecer a excentricidade e a pluralidade constitutivas do social e teria que apresentar-se como ethos e

10 Idem, p. 38

11llse Scherer-Warren e Paulo Krischke. Apresentação. In: Ilse Scherer-Warren e Paulo Krischke (orgs.) Uma Revolução no Cotidiano? Op. cit., p. 7. Nos anos 90 a "interação com o Estado" passou à frente na escala de prioridades dos movimentos, o que ambos os autores reconhecem em obras posteriores.

$\overline{16}$ As novas faces do socialismo burguês 
projeto político e "não como promessa messiânica de redenção universal":12

O socialismo atual deve abandonar todo anelo por um saber verdadeiro e onicompreensivo, vício da vertente 'mórbida' do racionalismo da Ilustração, que pretendia submeter o real - pela força, se necessário - a um modelo totalizador alimentado por uma obsessão por encontrar uma ordem e um sentido definitivo para a História, o Ser e a Sociedade. ${ }^{13}$

Posteriormente, o foco dos intelectuais dos movimentos sociais se deslocou das questões de identidade e epistemológicas para o terreno da democracia e da construção de uma nova esfera pública na América Latina, apresentadas como novidades históricas. Os movimentos sociais passaram a ser considerados como produtores do novo na medida em que fundam uma nova contratualidade social baseada no reconhecimento recíproco entre sujeitos portadores de direitos. No contexto latinoamericano, marcado pela persistência das várias formas de autoritarismo social, esta seria uma importante novidade. ${ }^{14} \mathrm{O}$ próprio Estado teria se redimensionado, passando a acolher a diversidade de conflitos que flui da sociedade civil. Ter-se-iam alterado os termos da relação entre Estado e Sociedade Civil: experiências de participação e representação teriam promovido a incessante democratização do Estado e a sedimentação de uma nova cultura política, democrática. A partir destas premissas é possível, inclusive, sustentar que não houve refluxo dos movimentos nos anos 90. Houve, sim, um processo de institucionalização (ONGs e conselhos, participação no Estado) e a criação de redes plurais ${ }^{15}$.

É preciso reconhecer que a construção histórica da modalidade democrática de dominação burguesa é, de fato, uma novidade para a América Latina. A partir dos anos 80 estabeleceu-se um período de relativa estabilidade institucional que, para países como o Brasil, foi o mais longo da sua história republicana. Que os movimen-

$--{ }_{--1}^{-}-$

12Benjamin Arditi. Discutir o Socialismo - A Condição Pós-Marxista. In: Sônia Laranjeira (org.) Classes e Movimentos Sociais... op. cit., p. 303.

13 Idem, p. 306.

14 Ver Maria Célia Paoli e Vera da Silva Telles. Direitos Sociais. Conflito e negociações no Brasil contemporâneo. Op. cit. e Evelina Dagnino. A Transformação nos Discursos e Práticas na Esquerda Latino-Americana. In:Sonia Alvarez, Evelina Dagnino e Arturo Escobar (orgs.). Cultura Política... op. cit. 15 Cf. Sérgio Gregório Baierle. A Explosão da Experiência... op. cit.

cadernos cemarx, $n^{0} 2-2005 \quad \mathbf{1 7}$ 
tos dos grupos subalternos sejam agentes históricos cruciais para a construção da ordem democrática, isto não é surpreendente em face da própria história do movimento operário no ocidente. Aspectos fundamentais incorporados à democracia burguesa, como a liberdade de organização e expressão e o sufrágio universal, foram objetivos permanentes da luta dos trabalhadores durante muitas décadas, em vários países, e na América Latina não foi diferente.

O que os mencionados autores perdem de vista, no entanto, é que, a despeito das mudanças nas formas políticas e institucionais, a dominação de classe permaneceu, no fundamental, inalterada. Recusando-se a pensar a problemática da exploração e dominação de classe, estes autores tendem a superestimar o caráter inovador das formas da prática política em construção na América Latina.

Por outro lado, o que é apresentado como novidade teórica (necessária para lidar com a novidade histórica) é, de fato, uma velharia liberal. O que está na base de conceitos como nova cidadania, nova esfera pública, invenção de direitos ou da democracia são os mesmos pressupostos da concepção procedimental, isto é, liberal de democracia. Pensada como procedimento, pura forma, a democracia "está sim aberta a todos os possíveis conteúdos", segundo Bobbio. ${ }^{16}$ Diante destes possíveis conteúdos a democracia seria neutra, desde que eles estejam comprometidos com o respeito às regras do jogo democrático. Para assegurar a formação das decisões que obrigam a todos, a democracia deve estar aparatada de normas para o processamento de conflitos. Ora, a condição lógica para que este mecanismo processador de conflitos produza decisões que obriguem a todos é que todos se reconheçam como iguais perante a democracia. Ao tomar como formalmente iguais aqueles que são objetivamente desiguais, esta concepção de democracia assume um dos postulados fundamentais do liberalismo e da visão burguesa de mundo.

A valorização e a legitimação dos conflitos, se postulada a partir da perspectiva liberal, corresponde ao estabelecimento de equivalência entre os pólos conflitantes (igualdade formal). Este pressuposto, no limite, obrigaria o movimento operário a reconhecer como legítima a posição do seu oponente e a renunciar à luta pela eliminação do conflito de classes. É certo que, historicamente, o movimento operário sempre lutou para assegurar o direito de expressar publicamente os conflitos com o capi-

$-\cdots-\cdots$

16 Norberto Bobbio. O Futuro da Democracia. Uma defesa das regras do jogo. 5ae ed., Rio de Janeiro, Paz e Terra, 1992, p. 12.

18 As novas faces do socialismo burguês 
tal. No entanto, se a interdição da expressão política do conflito entre o capital e o trabalho foi alvo constante da contestação operária, a premissa da legitimação dos conflitos e seu modelo de processamento democrático, em sua concepção liberal, aniquila o projeto de extinção da burguesia como classe, e das classes em geral. Ou seja: se é verdade que a luta de classes possui requerimentos democráticos, trata-se, porém, de uma concepção não-liberal de democracia.

A acomodação aos limites estruturais do capitalismo é a marca permanente do pensamento burguês, mesmo quando se apresenta como "de esquerda" ou socialista. Esta condição define as semelhanças de base entre o programa dos socialistas burgueses criticados pelo Manifesto em 1848 e as implicações políticas das teses sobre os NMS. Sobre ambos se pode dizer que pretendem "remediar os custos sociais para garantir a continuidade da sociedade burguesa". Ambos têm em comum a forma burguesa de realismo que consiste em "conceber o mundo em que [a burguesia] domina como o melhor dos mundos possíveis". Por isso quando convidam o proletariado a "dirigir-se completamente a uma nova Jerusalém social, de fato o convida a permanecer na sociedade atual, eliminando, porém, seu ódio contra a burguesia". ${ }^{17} \mathrm{O}$ socialismo burguês não deixa de falar em mudança nas condições materiais de existência, assim como os intelectuais dos NMS não param de apontar as virtualidades mudancistas da luta por direitos na nova esfera pública. Mas é facilmente verificável que dentre essas mudanças não figura a

abolição das relações burguesas de produção, que só pode ser realizada pela revolução, mas reformas administrativas, fundamentadas na existência dessas relações; tais reformas, portanto, não afetam as relações entre o capital e o trabalho, mas, na melhor das hipóteses, diminuem os custos da burguesia. ${ }^{18}$

As classes subalternas não foram ainda capazes de derrotar o processo de dominação - e isto se deve, em parte, a que não se propuseram/propõem este objetivo. Um problema, portanto, de direção política das lutas, precisamente o terreno em que operam os intelectuais dos novos movimentos sociais. Da definição do

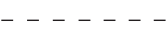

17 Karl Marx e Friedrich Engels. Manifesto do Partido Comunista. In: Harold J. Laski. O Manifesto Comunista de

Marx e Engels. 3a. ed., Rio de Janeiro, Zahar, 1982, p. 119.

18 Idem, pp. 119-20.

cadernos cemarx, $n^{0}-2-2005 \quad \mathbf{1 9}$ 
sentido e da direção das lutas da classe trabalhadora depende, hoje como no século XIX, o destino histórico da humanidade. Lutar por um rumo socialista para as lutas implica, portanto, em fazer a crítica das interpretações burguesas e dos projetos políticos de que elas são portadoras.

20 marxismo heterodoxo de João Bernardo 